\title{
Assistência em oncologia no Sistema Único de Saúde - SUS
}

\author{
Simone Costa BANNA ${ }^{(1)}$ \\ Brunna Verna Castro GONDINHO ${ }^{(1)}$
}

Recebido: 28 jan 2019

Aceito: 10 fev 2019

Autor de

correspondência:

si.banna.1967@gmail.com

Conflito de interesses: Os autores declaram não haver nenhum interesse profissional ou pessoal que possa gerar conflito de interesses em relação a este manuscrito.
(1)Faculdade de Saúde Pública, Universidade de São Paulo - USP, São Paulo, SP, Brasil.

\section{Resumo}

A Política Nacional para Prevenção e Controle do Câncer - PRONON está estruturada e organizada em uma linha de cuidados que perpassa todos os níveis de atenção, desde a atenção básica até a atenção especializada de média e alta complexidade, e de atendimento contemplados pela política (promoção, prevenção, diagnóstico, tratamento, reabilitação e cuidados paliativos). No Brasil, a atual distribuição dos diferentes tipos de cânceres sugere uma polarização epidemiológica em andamento. Com o recente envelhecimento da população, que projeta o crescimento exponencial de idosos, é possível identificar um aumento expressivo na prevalência do câncer, o que demanda dos gestores do Sistema Único de Saúde - SUS imenso esforço para a oferta de atenção adequada aos doentes. Esta perspectiva deixa clara a necessidade de grande investimento na promoção da saúde e na busca da modificação dos padrões de exposição aos fatores de risco para o câncer. Ao mesmo tempo em que é nítido o aumento da prevalência de cânceres associados ao melhor nível socioeconômico - mama, próstata, cólon e reto -, simultaneamente, tem-se taxas de incidência elevadas de tumores geralmente associados à pobreza: colo do útero, pênis, estômago e cavidade oral. Esta distribuição certamente resulta de exposição diferenciada a fatores ambientais relacionados ao processo de industrialização, como agentes químicos, físicos, biológicos e das condições de vida, que variam de intensidade em função das desigualdades sociais. Com a finalidade de direcionar recursos para prevenção e combate ao câncer no Brasil, em 2012 foi criado pelo Governo Federal, através da Lei $n^{\circ} 12.715$, o Programa Nacional de Apoio à Atenção Oncológica, apelidado de PRONON. Na Oncologia, o SUS atende os pacientes que necessitam de tratamento, através de uma Rede de Atenção Oncológica que inclui hospitais denominados Unidade de Assistência de Alta Complexidade em Oncologia - Unacon ou Centro de Assistência de Alta Complexidade em Oncologia - Cacon e estabelecimentos de saúde não hospitalares autorizados, com Serviços de Radioterapia e Quimioterapia. Os hospitais habilitados como Unacon ou Cacon fazem assistência às sete modalidades, que devem atuar integralmente: diagnóstico, cirurgia, radioterapia, quimioterapia (oncologia clínica, hematologia e oncologia pediátrica), medidas de suporte, reabilitação e cuidados paliativos, sendo que a reabilitação e os cuidados paliativos, para conforto e comodidade dos doentes, podem ser 
prestados em rede, conforme a decisão pactuada dos gestores estaduais e municipais. O Programa funciona mediante a aprovação, pelo Ministério da Saúde, de projetos apresentados por instituições credenciadas, sendo que os recursos são obtidos através de incentivo fiscal, no qual o Governo abre mão de parte do Imposto de Renda devido por empresas ou pessoas físicas. Para receber recursos pelo PRONON, o projeto deve estar compreendido em um dos três campos de atuação: (i) formação, treinamento e aperfeiçoamento de recursos humanos, para fins deste estudo denominado de Formação; (ii) pesquisas clínicas, epidemiológicas e experimentais, denominado Pesquisa; e (iii) prestação de serviços médico assistenciais, denominado Assistência. Os parâmetros para o planejamento e avaliação de estabelecimentos de saúde habilitados como Cacon e Unacon seguem a Portaria $n^{\circ} 874 / G M / M S$, de 2013. $O$ atendimento ao paciente oncológico está amplamente distribuído pelo território nacional, com forte concentração nos maiores centros, e indícios de escassez de atendimento mesmo nas regiões onde a oferta de serviços é maior. Grande proporção das pacientes reside a mais de $150 \mathrm{~km}$ do local de atendimento. A identificação das redes constitui ferramenta com aplicação importante no planejamento e na melhoria da distribuição dos serviços, considerando que o acesso geográfico é relevante para o desfecho do tratamento. A redução das taxas de morbidade e mortalidade depende da identificação precoce, pois, uma vez identificado o caso, o tratamento adequado e ágil concorre para reduzir os impactos da doença. Pacientes com câncer necessitam superar barreiras sociais, econômicas e psicológicas. Assim como a proximidade do serviço de saúde interfere na precocidade do diagnóstico 16, a distância percorrida pelo paciente deve ser considerada no tratamento, já que este exige repetidas visitas aos serviços de saúde para atendimento ambulatorial e internação. Neste sentido, a localização do serviço e dos usuários, os meios de transporte disponíveis, a distância, o tempo e os custos envolvidos no deslocamento devem ser considerados na avaliação do padrão de acessibilidade 17. Em um país com as dimensões do Brasil, a distribuição desigual da população e dos serviços de saúde no território marca um desafio a ser enfrentado. Na atenção terciária, a concentração dos recursos diagnósticos e terapêuticos, desejável para garantir maiores volumes e melhor qualidade do atendimento, muitas vezes impõe extensos deslocamentos a uma parcela considerável da população. Objetivo: realizar um estudo sobre a assistência em oncologia no SUS, desde sua aplicação ao acompanhamento dos serviços que compõem este sistema de saúde. Método: como método será utilizada a revisão integrativa, baseada em revisão sobre a assistência em oncologia, no âmbito do SUS, levantando a produção científica disponível através da busca sistematizada em plataforma de bases de dados da Saúde. A busca sistematizada foi realizada na plataforma da Biblioteca Virtual de Saúde - BVS (http://bvsalud.org/), partindo-se da técnica de funil, combinando-se diversos descritores relacionados ao tema e utilizando-se as sintaxes necessárias para refinar a busca. A composição sintática realizada do tema parte da compreensão de quatro polos temáticos de interesse, identificados a partir da pergunta da 
pesquisa: "O que os estudos na literatura científica destacam sobre a assistência em oncologia no SUS". Considerações finais: atende a esse requisito principalmente a busca utilizando os operadores booleanos (OR e AND) totalizando 33 estudos identificados com texto completo, cuja sintaxe final é: "Gastos em saúde" $O R$ "Gastos de capital" $O R$ "Controle de custos" $O R$ "Financiamento pessoal" $O R$ "Custos de medicamentos" $O R$ "Assistência à saúde" $O R$ "Cuidados Paliativos" $O R$ "Financiamento da assistência à saúde" $O R$ "Pacotes de assistência ao paciente" $O R$ "Institutos de câncer" $O R$ "Serviço hospitalar de oncologia" )) $A N D$ (mh:("Sistema único de saúde"). Nota-se, a partir de uma análise preliminar destes estudos, que todos os artigos são brasileiros.

Descritores: Gastos em Saúde; Assistência; Oncologia; Sistema Único de Saúde. 